Background: Cell-wall components of Gram-positive and Gram-negative bacteria induce the production of cytokines in human peripheral blood mononuclear cells. These cytokines are the main mediators of local or systemic inflammatory reaction that can contribute to the development of innate immunity.

Aims: This study was performed to analyze the involvement of CD14 molecule in the activation of human monocytes by peptidoglycan monomer (PGM) obtained by biosynthesis from culture fluid of penicillin-treated Brevibacterium divaricatum NRLL2311.

Methods: Cytokine release of interleukin (IL)-1, IL-6 and tumor necrosis factor-alpha from human monocytes via soluble CD14 (sCD14) or membrane-associated (mCD14) receptor using anti-CD14 monoclonal antibody (MEM-18) or lipid A structure (compound 406) was measured in bioassays.

Results: The results demonstrated that PGM in the presence of human serum might induce the monokine release in a dose-dependent manner. The addition of sCD14 at physiologic concentrations enhanced the PGM-induced monokine release, while the monokine inducing capacity of PGM in the presence of SCD14 was inhibited by MEM-18. Effects of PGM were also blocked by glycolipid, compound 406 , suggesting the involvement of binding structures similar to those for lipopolysaccharide.

Conclusion: Activation of human monocytes by PGM involves both forms of CD14 molecule, sCD14 and mCD14.

Keywords: Peptidoglycan monomer, Peptidoglycan, Lipopolysaccharide, CD14, Membrane CD14, Soluble CD14, Anti-CD14 monoclonal antibody, Compound 406, Monocytes, Cytokines

\section{The involvement of CD14 in the activation of human monocytes by peptidoglycan monomers}

\author{
Damir Muhvić1,CA, Volker El-Samalouti ${ }^{2}$, \\ Hans-Dieter Flad ${ }^{2}$, Biserka Radošević-Stašić ${ }^{1}$ and \\ Daniel Rukavina ${ }^{1}$
}

${ }^{1}$ Department of Physiology and Immunology, Medical Faculty, University of Rijeka, 51000 Rijeka, Croatia; ${ }^{2}$ Department of Immunology and Cell Biology, Research Center Borstel, 23845 Borstel, Germany

\author{
${ }^{\mathrm{CA}}$ Corresponding Author \\ Tel: (+) 38551651151 \\ Fax: (+) 38551675699 \\ E-mail: damirm@mamed.medri
}

\section{Introduction}

Cell wall components of Gram-negative and Grampositive bacteria have been reported to induce inflammatory responses in vivo, as well as in vitro. ${ }^{1-5}$ When localized, this inflammation helps to eradicate the invading organisms at the infected site, but in severe situations the release of soluble cellular mediators and dysfunction of numerous host defense factors may result in systemic inflammation that causes organ damage, sepsis, and death. Septic shock is a classical response to severe infections due to Gram-negative bacteria and its principal component lipopolysaccharide (LPS). ${ }^{6-8}$ Similar events, however, may also be provoked by Gram-positive bacteria ${ }^{9}$ containing, in cell walls, predominantly thick peptidoglycans (PG), which may also be obtained in the soluble form (sPG), after the treatment of growing bacteria by $\beta$-lactam antibiotics. ${ }^{10,11}$ Chemically, $P G$ is an alternating linked
$N$-acetylmuramyl and $N$-acetylglucosaminyl glycan whose residues are cross-linked by short peptides. ${ }^{10-13}$ Soluble PG, obtained from staphylococci, consists of disaccharide-peptapeptide polymers linked together via 1-4 $4^{\beta}$-glycosidic bonds, without the interpeptide bridges, due to the action of penicillin. ${ }^{10-13}$ All these components, similar to lipoteichoic acid (LTA), lipoarabinomannan, and other glycosyl residue-containing compounds, stimulate the release of proinflammatory mediators in the host from various cell types. ${ }^{1-9}$ However, although it is evident that PG has, in principle, the same inflammatory activity as LPS, the knowledge on the contribution of PG in distinct inflammatory reaction, as well as the mechanisms of its signal transduction in lymphoid cells, is limited. Evidence shows that activation of cells by PG is a receptor-mediated process involving the binding of PG to membranous CD14 (mCD14), ${ }^{1-14}$ and to the additional signal transducing receptors, belonging to the Toll-like 
receptor family. ${ }^{15-19}$ However, although both LPSand PG-mediated signals seem to activate similar types of receptors, the type of signal and coreceptors may differ, resulting in different requirement of serum factors and activation of different sequences in the region of CD14. ${ }^{20,21}$

Since there is still a paucity of data regarding the mechanisms leading to inflammatory response induced by Gram-positive bacteria, in spite of the fact that in recent years they have caused nosocomial infections and shock more frequently than Gramnegative bacteria, ${ }^{22}$ in the present study we tested the effects of peptidoglycan monomer (PGM), obtained by biosynthesis from culture fluids of penicillintreated Brevibacterium divaricatum NRRL-2311 23,24 on cytokine production of human peripheral blood mononuclear cells and on the involvement of soluble (sCD14) and mCD14 in these events. PGM represents a water-soluble monomeric structural subunit of the polymeric PG, consisting of $\beta 1,4$-linked $N$-acetylmuramic acid- $N$-acetyl-D-glucosamine disaccharide carrying the pentapeptid. Its immunostimulating and anti-metastatic activities were emphasized in many experimental protocols, ${ }^{25-28}$ but its action is still unclear. The data showed that PGM has a cytokine-stimulating capacity in vitro, leading to release of interleukin (IL)-1, IL-6, and tumor necrosis factor- $\alpha(\mathrm{TNF}-\alpha)$ in the presence of human serum or sCD14. Since the effects were blocked by anti-CD14 monoclonal antibodies (MEM-18) and by lipid A partial structure (compound 406), the data also suggest the involvement of both forms of CD14 molecules in these events.

\section{Materials and methods}

\section{Cell wall components}

PGM ( $N$-acetyl-glucosaminyl- $\beta-(1 \rightarrow 4)$ - $N$-acetyl-muramoyl-L-alanyl-D-isoglutaminyl- L-meso-diaminopimelyl(D-amide)-(L)-D-alanyl-D-alanine), a disaccharide pentapeptide from Gram-positive bacteria $B$. divaricatum, was isolated and purified as described elsewhere. ${ }^{23,24}$ It contained less than $2.25 \mathrm{pg}$ of endotoxin per $\mathrm{mg}$ of PGM, which was determined by the Limulus Amebocyte Lysate (LAL) assay (Haemochrom Diagnostica GmbH, Essen, Germany). LPS was isolated from Salmonella friedenau and purified by the phenolchloroform-petroleum ether method. ${ }^{29}$ This preparation contained less than $0.2 \%$ of protein and nucleic acids as determined by chemical analysis.

Synthetic compound 406 (precursor Ia), a tetra-acyl partial structure of Escherichia coli hexa-acyl lipid A lacking dodecanoic and tetradecanoic acids, was synthesized as described previously. ${ }^{30}$ Compound 406 was kindly provided by Dr S. Kusumoto, Department of Chemistry, Faculty of Science, Osaka University, Osaka, Japan.

\section{Antibodies}

The CD14-specific monoclonal antibody (murine hybridoma MEM-18 producing immunoglobulin (Ig)G1 monoclonal antibody) was kindly provided by Dr Václov Horejší, Institute of Molecular Genetics, Academy of Sciences of the Czech Republic, Prague, Czech Republic. ${ }^{31}$ Purified mouse IgG1 (MOPC21; Sigma GmbH, Deisenhofen, Germany) was used as an antibody isotype control.

\section{Recombinant human soluble CD14}

Recombinant human soluble CD14 (sCD14) ${ }^{32}$ was purified from serum-free culture supernatant of sCD14-transfected CHO cells by affinity chromatography (kindly provided by Dr F. Stelter, Institut of Immunology and Transfusion Medicine, University of Greifswald, Greifswald, Germany).

\section{Cell isolation and induction of TNF, IL-1 and IL-6 release}

Human blood from different healthy donors (permission was obtained from the Local Ethical Committee) was collected in heparin $(10 \mathrm{U} / \mathrm{ml})$. The mononuclear cells (MNC) were isolated by density-gradient centrifugation on Ficoll-Paque (Pharmacia, Uppsala, Sweden) as described elsewhere. ${ }^{33}$ After being washed three times, MNC $\left(4 \times 10^{6} / \mathrm{ml}\right)$ were suspended in RPMI 1640 supplemented with $100 \mathrm{U} / \mathrm{ml}$ of penicillin and $100 \mu \mathrm{g} / \mathrm{ml}$ of streptomycin (RPMI-1640-M). The cells were stimulated for $8 \mathrm{~h}$ at $37^{\circ} \mathrm{C}\left(5 \% \mathrm{CO}_{2}\right)$ in $200 \mu 1$ cultures with an appropriate cytokine inducer in the presence or absence of $10 \%$ heat-inactivated human serum (HS) in U-bottomed microtiter plates (Greiner, Nürtingen, Germany). All cultures were carried out in triplicate. After incubation, supernatants were harvested and stored at $-20^{\circ} \mathrm{C}$ until analyzed for IL-1, IL-6 or TNF activity. In the inhibition experiments with anti-CD14 monoclonal antibody (mAb) or compound 406, MNC were first pretreated for $1 \mathrm{~h}$ with these compounds on ice, after which the stimulus (PGM or LPS) was added. To investigate the effect of sCD14, PGM or LPS were first preincubated for $3 \mathrm{~h}$ with sCD14 and then added to MNC $(4 \times$ $10^{6} / \mathrm{ml}$ ) in RPMI-1640-M without HS.

\section{Determination of TNF, IL-1 and IL- 6 bioactivity}

TNF and IL-1 were determined in bioassays as described elsewhere. ${ }^{33,34}$ In brief, TNF cytotoxic activity in culture supernatants was measured using the TNF-sensitive L929 fibrosarcoma cell line. In the IL-1 bioassay, the proliferation-inducing activity of the culture supernatant from human foreskin dermal fibroblasts was determined. ${ }^{34}$ IL-6 activity was 

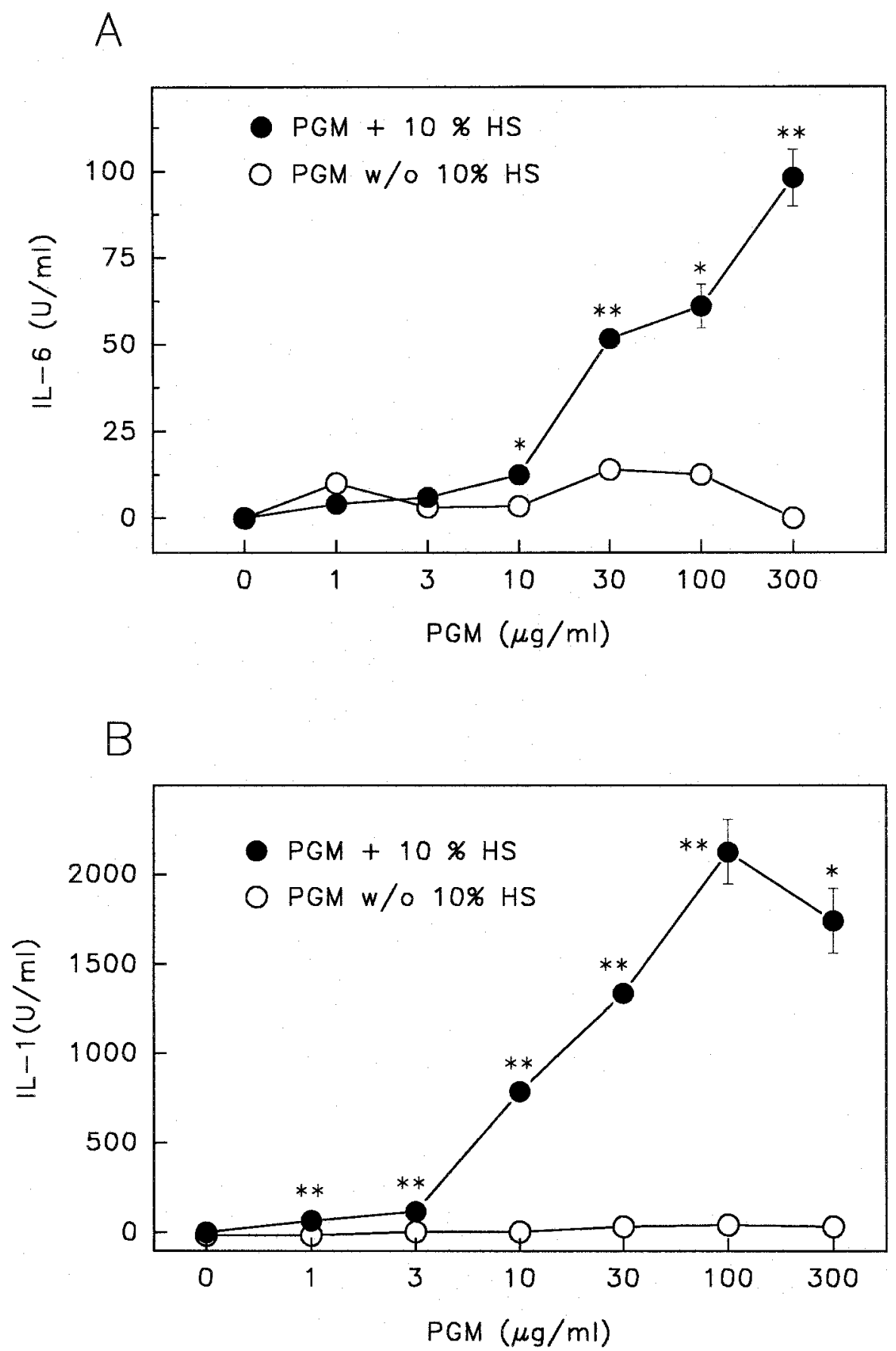

FIG. 1. Induction of IL-6 and IL-1 release from mononuclear cells (MNC) by peptidoglycan monomer (PGM) in the presence or absence of human serum (HS). MNC $\left(4 \times 10^{6} / \mathrm{ml}\right)$ were stimulated with increasing concentrations of PGM in the presence or absence of $10 \% \mathrm{HS}$ for $8 \mathrm{~h}$. The supernatants were harvested, and (A) IL-6 or (B) IL-1 were measured in bioassays. The data represent the mean of triplicates \pm SEM from one of three identical experiments. ${ }^{*} p<0.05,{ }^{*} p<0.01, \mathrm{PGM}+10 \% \mathrm{HS}$ versus PGM without (w/o) $10 \%$ HS.

determined by the IL-6-dependent B9.9-3A4 cell proliferation assay. ${ }^{35}$ The TNF, IL-1, and IL-6 activities in the samples were determined by probit analysis using a standard preparation of recombinant human TNF- $\alpha$, IL- $1 \beta$ or IL- 6 , respectively. ${ }^{36}$ The results were calculated to units per milliliter of TNF$\alpha$, IL-1, and IL-6, respectively. The following agents did not induce release of these cytokines after addition to monocytes: human serum, compound 406, anti-CD14 mAb (MEM-18), and human recombinant soluble sCD14.

\section{Statistical analysis}

Results were analyzed using the SigmaPlot Scientific Graphing System Version 5.0 Jandel Corporation, 
Table 1. The effects of soluble CD14 (sCD14) and anti-CD14 monoclonal antibody (MEM-18) on IL-1 release from human mononuclear cells (MNC) stimulated with peptidoglycan monomer (PGM) or lipopolysaccharide (LPS)

\begin{tabular}{lcr}
\hline Stimulation of MNC in the presence of: & \multicolumn{2}{c}{ IL-1 release (U/ml) after stimulation } \\
with:
\end{tabular}

The results are means SEM of triplicates from one out of three separate experiments.

${ }^{*} p<0.001$ versus the same substance with $\operatorname{lgG} 1+\operatorname{sCD} 14 ; \dagger p<0.001$ versus the same substance without sCD14.

USA). The test for significance used in all cases was Student's $t$-test.

\section{Results}

\section{PGM induces IL-6 and IL-1 release from} cultured MNC

Human MNC were treated for $8 \mathrm{~h}$ with various concentrations of PGM in the presence or absence of $10 \%$ HS. As shown in Figure 1, PGM stimulated the release of only small amounts of IL-6 (Fig. 1A) or IL-1 (Fig. 1B) in the absence of HS. However, after the addition of $10 \% \mathrm{HS}$, the statistically significant $(p<0.05$ and $p<0.01)$ dose-dependent increase in the cytokine concentrations was noticed in supernatants of PGM-stimulated MNC (Fig. 1). A similar dose-dependent effect of PGM was obtained on the secretion of TNF (data not shown), pointing to the role of sCD14 in PGM-induced release of inflammatory cytokines from human monocytes.

sCD14 increases both the PGM- and LPS-induced IL-1 release from human monocytes, and anti$\mathrm{CD} 14 \mathrm{mAb}$ inhibits this process

To prove the role of SCD14 in PGM-induced release of monokines and to compare this process with that induced by LPS, PGM or LPS were preincubated with sCD14 for $3 \mathrm{~h}$ and then added to cultures of human monocytes in additional experiments. The concentration of IL-1 found in these cultures was compared with that found in cultures without added sCD14, with those treated with antiCD14 mAb MEM-18, and with those treated with anti-IgG1 mAb. As presented in Table 1, the addition of sCD14 significantly enhanced the potential of both PGM $(p<0.001)$ and LPS $(p<0.001)$ to release the IL-1 from monocytes, and anti-CD14 mAb (significantly, $p<0.001$ ) almost completely blocked this process, while an isotype control (anti-IgG1 mAb) did not block PGM- or LPS-induced cytokine production.
Anti-CD14 mAb inhibits PGM- and LPS-induced TNF release from MNC

To elucidate the potential role of mCD14, in the further experiment, we preincubated human MNC with increasing concentrations of anti-CD14 mAb (MEM-18) or anti-IgG1 mAb before the addition of PGM (Fig. 2A) or LPS (Fig. 2B). As shown in Fig. 2A,B, anti-CD14 mAb significantly blocked the TNF production in supernatants of PGM $(p<0.01)$ or LPS $(p<$ $0.01)$ stimulated cultures, while an isotype control did not have an inhibitory effect on PGM- or LPS-induced cytokine production. This indicates that antiCD14 mAb may abolish PGM-induced and LPSinduced TNF production.

The release of TNF from MNC induced by PGM or LPS was completely inhibited by lipid A partial structure (compound 406)

To partially define the PGM binding structures on the membrane, human MNC were pretreated with increasing concentrations of compound 406 , which is a partial lipid A structure. The data showed that compound 406 was able to significantly decrease or abolish $(p<0.001)$ both PGM- and LPS-induced TNF production (Fig. 3), indicating that PGM uses similar receptor structures as LPS during the activation of human monocytes.

\section{Discussion}

In contrast to Gram-negative bacteria, the knowledge about the cytokine induction due to the adhesion of Gram-positive bacteria to human MNC is limited and concentrated mostly on the mechanisms of action of SPG, muramyl dipeptide (MDP) or LTA. 2,5,9-13,16,19 The signaling mechanisms induced by water-soluble, monomeric glycopeptides, such as PGM, are even less known, although it has been repeatedly shown that this product might have very useful immunostimulating abilities. ${ }^{24-28}$ The data presented herein therefore represent, to our knowl- 

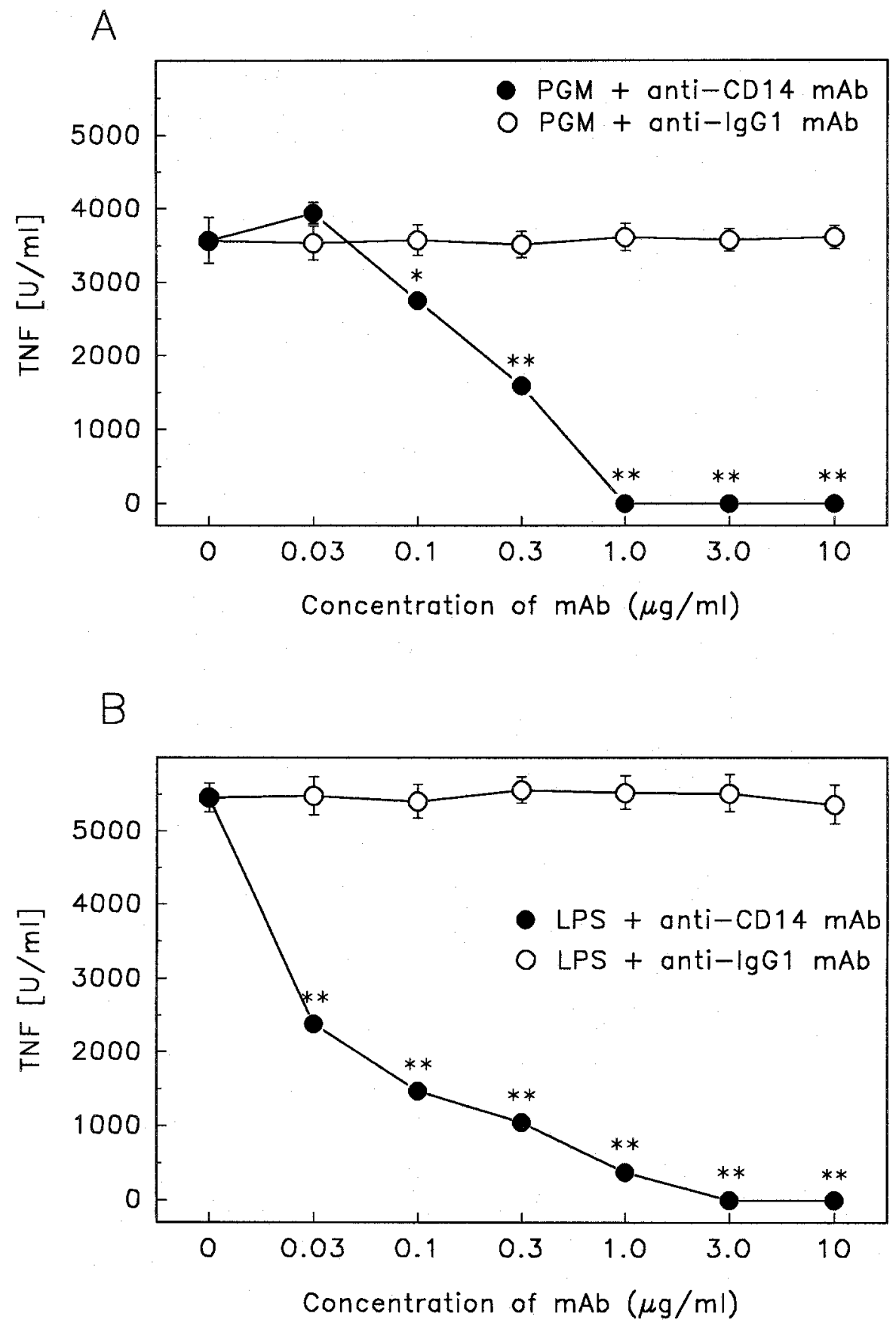

FIG. 2. Inhibition of peptidoglycan monomer (PGM)- and lipopolysaccharide (LPS)-induced tumor necrosis factor (TNF) release in mononuclear cells (MNC) by anti-CD14 monoclonal antibody (mAb) (MEM-18). MNC $\left(4 \times 10^{6} / \mathrm{ml}\right)$ were preincubated with increasing concentrations of anti-CD14 mAb (MEM-18) or purified mouse IgG1 (MOPC21), which was used as an antibody isotype control for $1 \mathrm{~h}$ at $4^{\circ} \mathrm{C}$ before stimulation with (A) PGM $(30 \mu \mathrm{g} / \mathrm{ml})$ or (B) LPS $(10 \mathrm{ng} / \mathrm{ml})$. After $8 \mathrm{~h}$ of incubation (in the presence of $10 \%$ human serum), supernatants were harvested and TNF activity was determined in the bioassay. Results represent the mean of triplicates \pm SEM from one of three identical experiments. ${ }^{*} p<0.05, * * p<0.01, \mathrm{PGM}+$ anti-CD14 mAb versus PGM + IgG1, LPS + anti-CD14 versus LPS + IgG1.

edge, the first evidence of the CD14-dependent cytokine production induced by PGM (disaccharidepentapeptide) on human MNC. The results emphasize that HS increases PGM-induced monokine production by human monocytes (Fig. 1), and clearly show that preincubation with sCD14 enhances, while anti-CD14 mAb (MEM-18) blocks, the PGM- induced release of IL-1 (Table 1). Furthermore, since it was found that MEM-18, similar to a lipid A partial structure (compound 406) (Fig. 3), may block the biological activity of PGM (Fig. 2), our data suggest that mCD14 is also involved in the PGM-induced cytokine release from MNC. Similar to this, unpublished data show that cytokine production in human 


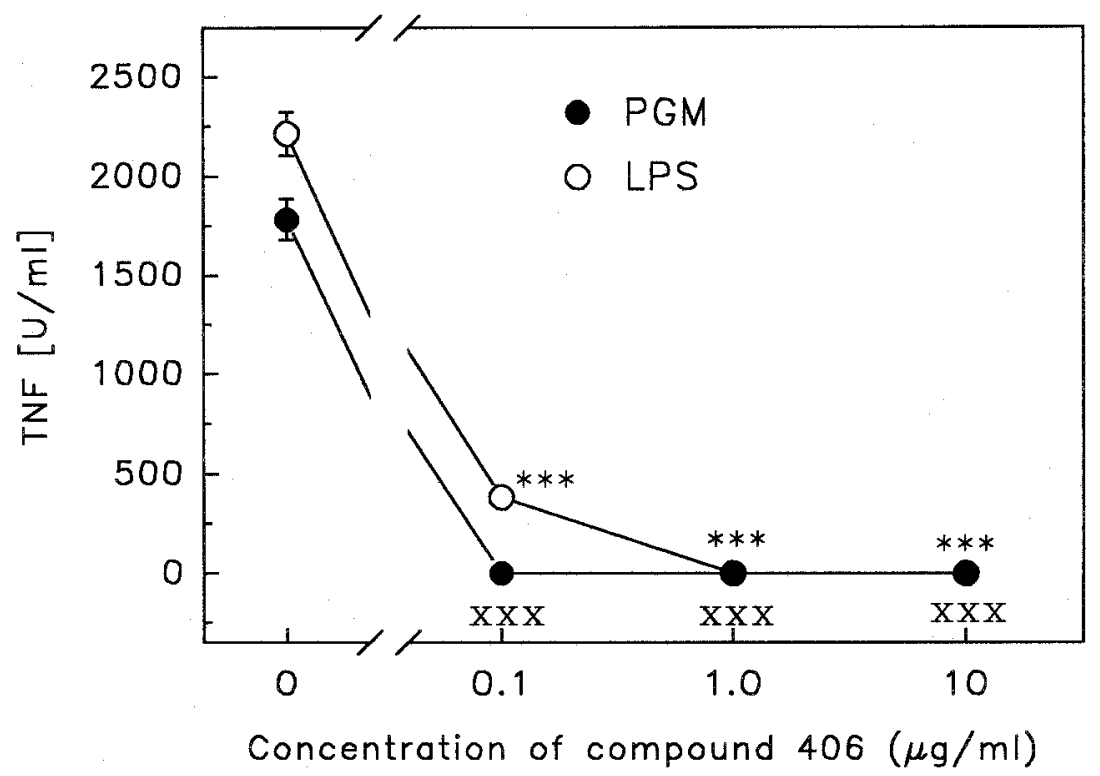

FIG. 3. Inhibition of tumor necrosis factor (TNF) release induced by peptidoglycan monomer (PGM) and lipopolysaccharide (LPS) from mononuclear cells $(\mathrm{MNC})$ by the compound 406 . MNC $\left(4 \times 10^{6} / \mathrm{ml}\right)$ were preincubated with increasing concentrations of compound 406 for $1 \mathrm{~h}$ at $4^{\circ} \mathrm{C}$ before stimulation with PGM $(30 \mu \mathrm{g} / \mathrm{ml})$ or LPS $(10 \mathrm{ng} / \mathrm{ml})$. After $8 \mathrm{~h}$ of incubation (in the presence of human serum), supernatants were harvested and TNF activity was detected in the bioassay. Results represent the mean of triplicates \pm SEM from one of three identical experiments. ${ }^{* *} p<0.001$, PGM versus PGM with compound 406; xxx $p<0.001$, LPS versus LPS with compound 406.

monocytes induced by MDP can be inhibited by anti-CD14 mAb (A.J. Ulmer, personal communication). Taken together, the data point to the similarity of action between PGM, MDP, SPG and LPS, and other bacterial products supporting the hypothesis that CD14 functions as a 'pattern recognition receptor' ${ }^{14}$ which probably recognizes shared features of all these agents. Moreover, similar to as it was shown for other Gram-positive peptidoglycans, ${ }^{10}$ the proinflammatory effects of PGM were less emphasized than that induced by LPS, since it was noticed in the presence of human serum that, for optimal cytokine production from the peripheral blood MNC, an approximately $10^{5}$ times higher concentration of PGM than of LPS ( $4 \log$ difference $(\mu \mathrm{g} / \mathrm{ml}))$ is required (unpublished data). The observed difference has been attempted to be explained by the existence of low affinity binding interaction between PGM and CD14 molecule, ${ }^{10-12}$ as well as by the hypothesis that PG is either less active than LPS or only a part of PG is required for PBMC activation. ${ }^{37}$

Our data obtained with PGM are in close agreement with results published by Weideman et al., ${ }^{10}$ which show similar binding characteristics of sPG. However, in the literature there is some disagreement about the determination of structures responsible for the activation of human monocytes by products of Gram-positive bacteria. Thus, although our data show that PGM, as the hydrophilic disaccharide-pentapeptide, has similar effects as hydrophilic $\quad N$-acetylmuramyl-L-alanyl-D-isoglutamine or
MDP, which in binding inhibition studies was also able to block the binding of fluorescein isothiocyanate-labeled SPG to human monocytes, ${ }^{10}$ in other experiments using the gel shift assay it was shown that soluble MDP did not bind to sCD14 and did not inhibit binding of SPG or LPS to SCD14. ${ }^{11}$ The reason for this difference is unclear, but it was hypothesized that polymeric, aggregated or solid-phase bound PG or MDP should be formed for high affinity binding to CD14 in a gel shift assay, which might not be created after the use of very hydrophilic synthetic PG fragments. ${ }^{11}$ This is also supported by our data showing that PGM also does not inhibit binding of sPG or LPS to sCD14 in the gel shift assay (unpublished data). As further support of our data, pointing to activities of soluble PGM, it was recently emphasized that digestion products of Streptococcus pneumoniae cell walls of a molecular weight between 600 and 15,000 might have different proinflammatory activities. ${ }^{37}$ Thus, a simple stem peptide $\left(M_{\mathrm{r}}<\right.$ 750) was 10-fold less active than undigested peptidoglycans, in contrast to tripeptides $\left(M_{\mathrm{r}}>1000\right)$, which were 100-fold more potent than the native material. Moreover, while one dipeptide was inactive, two tripeptides were active, pointing to the possibility that complex branched peptides, which represent only $2 \%$ of the total material, were responsible for peptidoglycan-induced inflammation. Owing to these facts, it was proposed that, to stimulate target cells, both soluble and cross-linked peptide must present at least three stem peptides in close proximity. ${ }^{37}$ 
Recent studies also provided unequivocal evidence that, for cellular responsiveness to SPG, the N-terminal 151 amino acids of mCD14 $4^{5,11}$ were sufficient, but the binding characteristics of hydrosoluble PGM were not fully elucidated. Our finding of dose-dependent, saturable, and anti-CD14 sensitive effects of PGM, however, directly points to involvement of CD14 (Figs. 1 and 2, and Table 1). Furthermore, since cytokine production induced by PGM was blocked by MEM-18 (Fig. 2), whose epitope is located between amino acids 51 and 64, there is also some possibility that these fragments were particularly responsible for the effects of our immunostimulating agent, similarly as it was found for SPG and LPS. ${ }^{11}$ Additionally, owing to the fact that there is structural similarity between PGM and lipid A with regard to GlcNAc-MurNAc and (GlcNAc-MurNac) ${ }_{2}$, respectively, it could be hypothesized that active parts of PGM were hydrophilic domains, exposed on the surface and available for binding to CD14.

Taken together, although further characteristics of the binding of PGM remain to be elucidated, our data provide the first evidence that, in the induction of cytokine production in human monocytes, not only the polymeric SPG, but also the monomeric hydrosoluble PGM are involved. For optimal activation, PGM required the presence of SCD14 or other human serum components and mCD14. In the further experiments, it must be clarified whether CD14 in these events acts as a 'pattern recognition' receptor, ${ }^{14}$ an unspecific carrier molecule, or as a contributor that, together with LPS-binding protein (LBP) in a 'combinatorial' scheme, participates in recognition of these and other bacterial products. ${ }^{3,11,14}$

ACKNOWLEDGEMENTS. The authors wish to thank Prof. Dr Hans-Dieter Flad for acceptance and financial support of D.M., who was a visiting scientist at the Department of Immunology and Cell Biology, Research Center Borstel, Borstel, Germany. The authors are also grateful to Prof. Dr E.Th. Rietschel and Prof. Dr A.J. Ulmer for stimulating discussion during preparation of this manuscript, as well as for permission to cite some unpublished data from their laboratory. D.M. also wishes to thank Dr Parvis Shayan for the performance of LAL tests, and Ina Goroncy, Katrin Klopfenstein, Carola Schneider and Tanja Hempel for their expert technical assistance. This work was partly supported by the grants from the Croatian Ministry of Science (numbers 006231 and 006202). For donation of PGM and its derivatives, we would like to thank the research staff of Pliva Pharmaceutical, Zagreb, Croatia.

\section{References}

1. Holst O, Ulmer AJ, Brade H, Flad HD, Rietschel ET. Biochemistry and cell biology of bacterial endotoxins. FEMS Immunol Med Microbiol 1996; 16: 83-104

2. Rietschel ET, Schletter J, Weidemann B, et al. Lipopolysaccharide and peptidoglycan: CD14-dependent bacterial inducers of inflammation. Microb Drug Resist Spring 1998; 4: 37-44.

3. Wright SD. CD14 and innate recognition of bacteria. J Immunol 1995; 155: 6-8

4. Tapping RI, Tobias PS. Soluble CD14-mediated cellular responses to lipopolysaccharide. Chem Immunol 2000; 74: 108-121.

5. Gupta D, Kirkland TN, Viriyakosol S, Dziarski R. CD14 is a cell-activating receptor for bacterial peptidoglycan. J Biol Chem 1996; 271: 23310-23316

6. Heumann D, Glauser MP, Calandra T. Molecular basis of host-pathogen interaction in septic shock. Curr Opin Microbiol 1998; 1: 49-55.

7. Glauser MP. Pathophysiologic basis of sepsis: considerations for future strategies of intervention. Crit Care Med 2000; 28 (suppl 9): S4-S8.

8. Downey JS, Han J. Cellular activation mechanisms in septic shock. Front Biosci 1998; 3: 468-476.

9. Sriskandan S, Cohen J. Gram-positive sepsis. Mechanisms and differences from gram-negative sepsis. Infect Dis Clin North Am 1999; 13: 397-412.

10. Weidemann B, Schletter J, Dziarski R, et al. Specific binding of soluble peptidoglycan and muramyldipeptide to CD14 on human monocytes. Infect Immun 1997; 65: 858-864.

11. Dziarski R, Tapping RI, Tobias PS. Binding of bacterial peptidoglycan to CD14. J Biol Chem 1998; 273: 8680-8690.

12. Dziarski R, Ulmer AJ, Gupta D. Interactions of CD14 with components of gram-positive bacteria. Chem Immunol 2000; 74: 83-107.

13. Gold M, Miller C, Mishell R. Soluble non-cross-linked peptidoglycan polymers stimulate monocyte-macrophage inflamatory functions. Infect Immun 1985; 49: 731-741.

14. Pugin J, Heumann ID, Tomasz A, et al. CD14 is a pattern recognition receptor. Immunity 1994; 1: 509-516.

15. Means TK, Golenbock DT, Fenton MJ. The biology of Toll-like receptors. Cytokine Growth Factor Rev 2000; 11: 219-232

16. Yoshimura A, Lien E, Ingalls RR, Tuomanen E, Dziarski R, Golenbock D. Cutting edge: recognition of Gram-positive bacterial cell wall components by the innate immune system occurs via Toll-like receptor $2 . J$ Immunol 1999; 163: 1-5.

17. Bowie A, O'Neill LA. The interleukin-1 receptor/Toll-like receptor superfamily: signal generators for pro-inflammatory interleukins and microbial products. J Leukoc Biol 2000; 67: 508-514.

18. Lien E, Means TK, Heine H, et al., Toll-like receptor 4 imparts ligandspecific recognition of bacterial lipopolysaccharide. J Clin Invest 2000; 105: 497-504

19. Schwandner R, Dziarski R, Wesche H, Rothe M, Kirschning CJ. Peptidoglycan- and lipoteichoic acid-induced cell activation is mediated by tolllike receptor 2. J Biol Chem 1999; 274: 17406-17409.

20. Dziarski R, Viriyakosol S, Kirkland TN, Gupta D. Soluble CD14 enhances membrane CD14-mediated responses to peptidoglycan: structural requirements differ from those for responses to lipopolysaccharide. Infect Immun 2000; 68: 5254-5260.

21. Dziarski R, Jin YP, Gupta D. Differential activation of extracellular signalregulated kinase (ERK) 1, ERK2, p38, and c-Jun NH2-terminal kinase mitogen-activated protein kinases by bacterial peptidoglycan. $J$ Infect Dis 1996; 174: 777-785.

22. Awada A, van der Auwera P, Meunier F, Daneau D, Klastersky J. Streptococcal and enterococcal bacteremia in patients with cancer. Clin Infect Dis 1992; 15: 33-48.

23. Keglevic D, Ladešic B, Tomašic J, Valinger Z, Naumski R. Isolation procedure and properties of monomer unit from lysozyme digest of peptidoglycan complex excreted into the medium by penicillin-treated Brevibacterium divaricatum mutant. Biochim Biophys Acta 1979; 585: $273-281$

24. Suškovic B, Vajtner Z, Naumski R. Synthesis and biological activities of some peptidoglycan monomer derivatives. Tetrabedron 1991; 47: 8407-8416.

25. Valinger Z, Ladešic B, Hršak I, Tomašic J. Relation of metabolism and and immunostimmulating activity of peptidoglycan monomer in mice after three different routes of administration. Int I Immunopharmacol 1987; 9: 325-332.

26. Gabrilovac J, Tomašic J, Boranic M, Martin-Kleiner I, Osmak M. In vivo and in vitro modulation of NK and ADCC activities of mouse spleen cells by peptidoglycan monomer (PGM). Res Exp Med 1989; 189: 265-273.

27. Radoševic-Stašic $\mathrm{B}$, Trobonjaca $\mathrm{Z}$, Petkovic $\mathrm{M}$, et al. Immunoregulating effects of peptidoglycan monomer linked with zinc in adult mice. Int Arch Allergy Immunol 1995; 106: 219-228.

28. Ravlić-Gulan J, Radošević-Stašić B, Trobonjača Z, Petković M, Ćuk M, Rukavina D. On the role of $T$ lymphocytes in stimulation of humoral immunity induced by peptidoglycan-monomer linked with zinc. Int Arch Allergy Immunol 1999; 119: 13-22.

29. Galanos C, Lüderitz O, Westphal O. Preparation and properties of a standard lipopolysaccharide from Salmonella abortus equi (NovoPyrexal). Zentralbl Bakteriol Mikrobiol Hyg I Abt Orig A 1979; 243: 226-244.

30. Imoto M, Yoshimura H, Yamamoto M, Shimamoto T, Kusumoto S, Shiba T. Chemical synthesis of a biosynthetic precursor of lipid A with a phosphorylated tetraacyldisaccharide structure. Bull Chem Soc JPn 1987; 60: 2197-2204.

31. Bažil V, Hořejši V, Baudyš M, et al. Biochemical characterisation of a soluble form of the 53-kDa monocyte surface antigen. Eur J Immunol 1986; 16: 1583-1589.

32. Stelter F, Pfister M, Bernheiden M, et al. The myeloid differentiation antigen CD14 is $\mathrm{N}$ - and O-glycosylated: contribution of $\mathrm{N}$-linked glycosylation to different soluble CD14 isoforms. Eur J Biochem 1996; 236: 457-464

33. Feist W, Ulmer AJ, Wang M-H, et al. Modulation of lipopolysaccharideinduced production of tumor necrosis factor, interleukin 1 , and interleukin 6 by synthetic precursor Ia of lipid A. FEMS Microbiol Immunol 1992; 89: 73-90. 
34. Loppnow H, Flad H-D, Dürrbaum I, et al. Detection of interleukin 1 with human dermal fibroblasts. Immunobiology 1989; 179: 283-291.

35. Wang M-H, Flad H-D, Feist W, et al. Inhibition of endotoxin-induced interleukin-6 production by synthetic lipid A partial structures in human peripheral blood mononuclear cells. Infect Immun 1991; 59: 4655-4664.

36. Gillis S, Ferm MM, Ou W, Smith KA. T cell growth factor: parameters of production and a quantitative microassay for activity. J Immunol 1978; 120: 2027-2032.
37. Majcherczyk PA, Langen H, Heumann D, Fountoulakis M, Glauser MP, Moreillon P. Digestion of Streptococcus pneumoniae cell walls with its major peptidoglycan hydrolase releases branched stem peptides carrying proinflammatory activity. J Biol Chem 1999; 274: 12537-12543.

Received 19 April 2001;

accepted 3 May 2001 


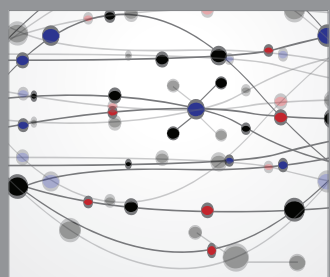

The Scientific World Journal
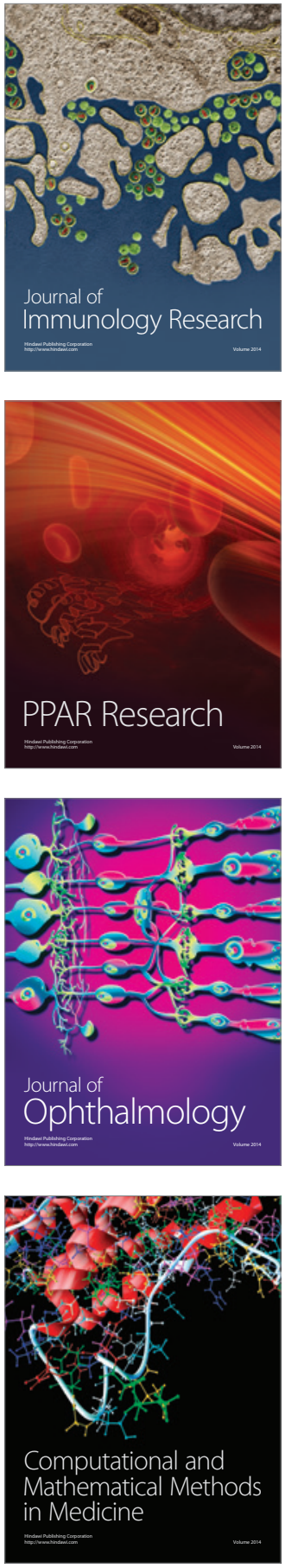

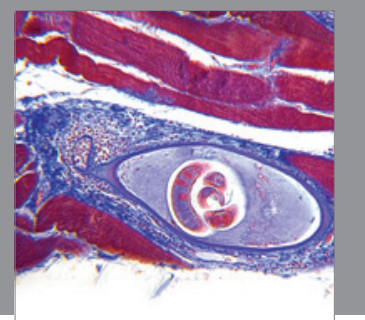

Gastroenterology

Research and Practice
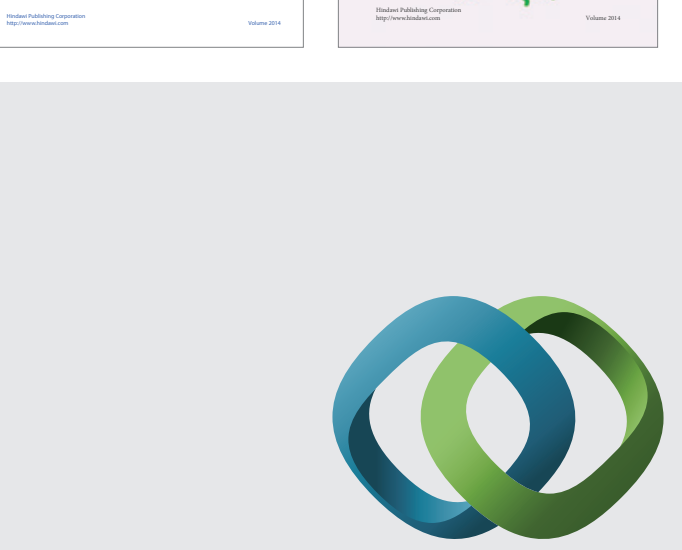

\section{Hindawi}

Submit your manuscripts at

http://www.hindawi.com
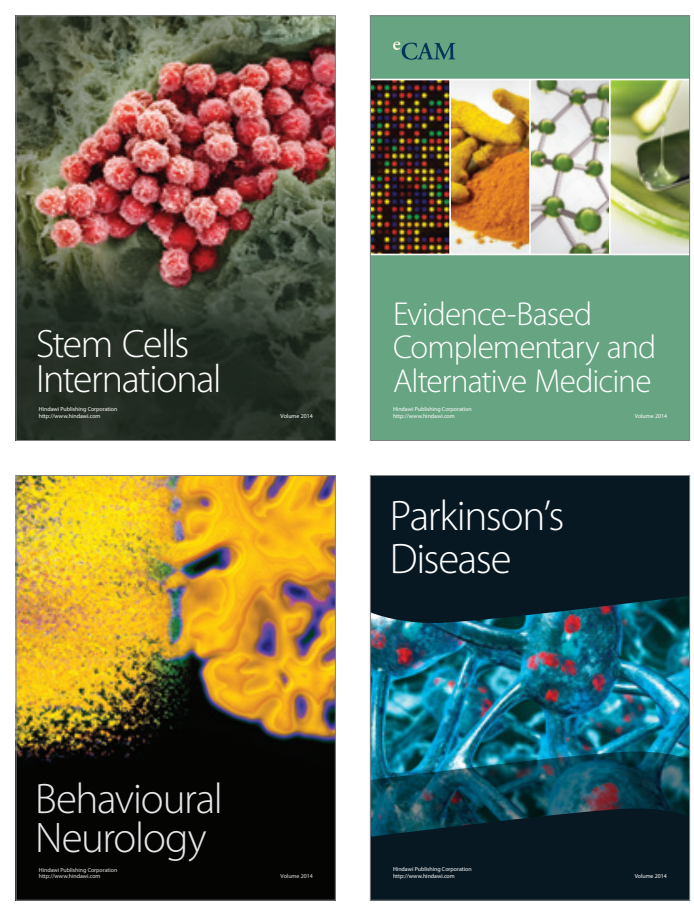

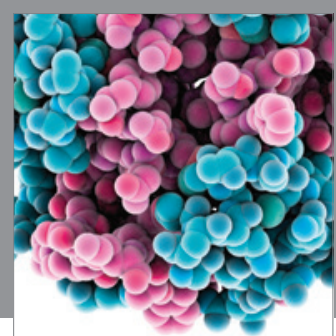

Journal of
Diabetes Research

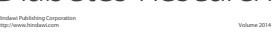

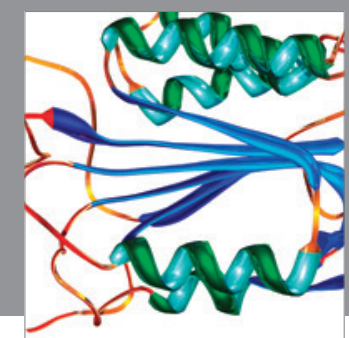

Disease Markers
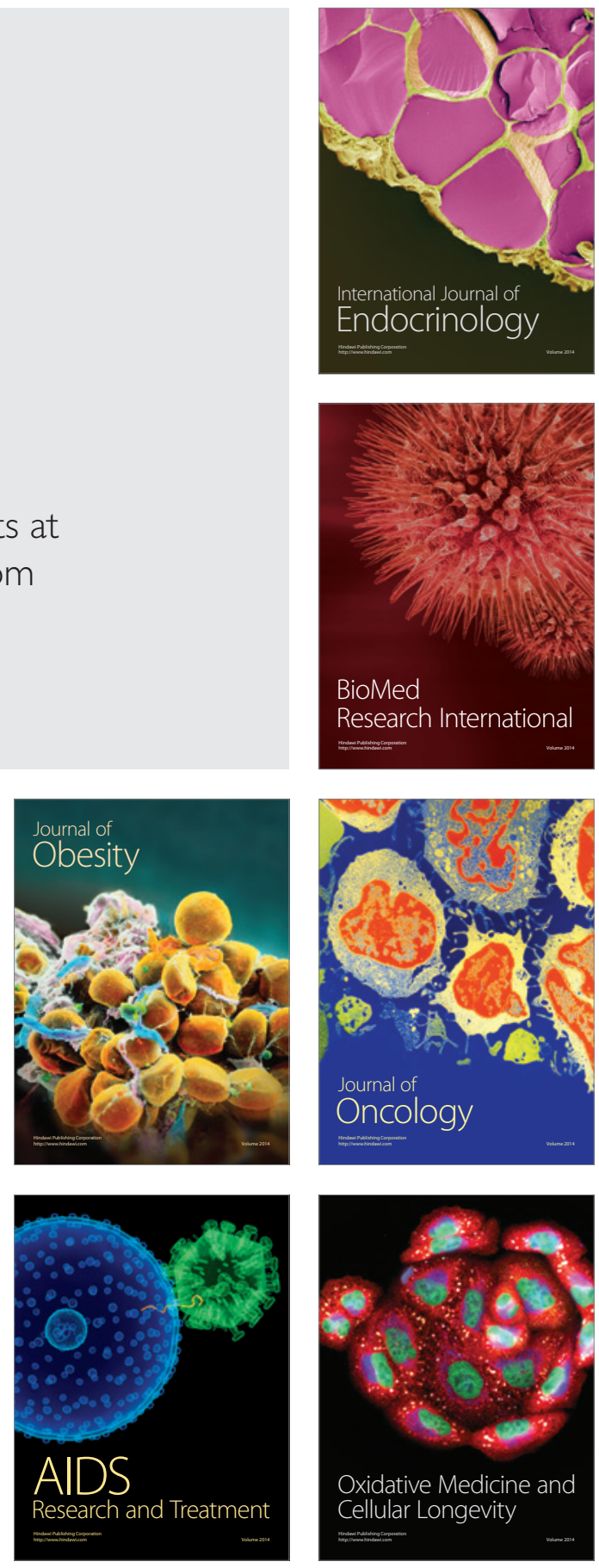